\title{
Simulation of pollution transport in buildings: the importance of taking into account dynamic thermal effects
}

Jonathon Taylor $^{1}$, Clive Shrubsole ${ }^{1}$, Phillip Biddulph ${ }^{1}$, Benjamin Jones ${ }^{2}$, Payel Das ${ }^{1}$, Michael Davies ${ }^{1}$

${ }^{1}$ Bartlett School of Graduate Studies, University College London, Central House, 14 Upper Woburn Place, London, WC1H 0NN, United Kingdom

${ }^{2}$ Department of Architecture and Built Environment, Lenton Firs House, University of Nottingham, NG7 2RD, United Kingdom

\begin{abstract}
The recent introduction of the Generic Contaminant Model in EnergyPlus allows for the integrated modelling of multizone contaminant and dynamic thermal behaviour within a single simulation package. This article demonstrates how dynamic thermal simulation can modify pollutant transport within a building. $\mathrm{PM}_{2.5}$ infiltration from the external to internal environment under dynamic thermal conditions is compared in CONTAM, EnergyPlus 8.0, and Polluto, an in-house pollutant transport model developed in EnergyPlus 3.1. The influence of internal temperature on indoor $\mathrm{PM}_{2.5}$ levels is investigated by comparing results from standard CONTAM simulations and dynamic thermal EnergyPlus 8 simulations. Circumstances where the predictions of such models can diverge are identified.
\end{abstract}




\section{Practical Application}

This technical note compares the performance of a new indoor air quality model in EnergyPlus, an EnergyPlus in-house model (Polluto), and an established model (CONTAM). The work then compares the results of indoor air quality models under static and dynamic internal temperature conditions, and demonstrates how predicted indoor pollution levels may deviate significantly if an inappropriate indoor temperature is used. Practically, the work provides confidence in the new models, as well as demonstrating the importance of having a good understanding of the thermal behaviour of a building when modelling indoor air quality.

\section{Introduction}

Airflow modelling is an essential tool in building design and analysis of indoor air quality. Air pollutants can be produced indoors by building occupants (e.g. water vapour, tobacco smoke, $\mathrm{CO}_{2}$ ), the building envelope and internal furnishings (e.g. Volatile Organic Compounds), and microbial contaminants of the building (e.g. mould spores); these pollutants can circulate around a building and require removal from the internal air through appropriate ventilation. Additionally, pollutants from the external environment such as fine particulate matter $\left(\mathrm{PM}_{2.5}\right)$ may infiltrate the building and require removal. Existing airflow tools can include simplistic 
single-zone models, more complex multizone models, and highly complex Computational Fluid Dynamics (CFD) models. In multizone airflow models, buildings are treated as a series of nodes representing zones within the building, and connections between nodes representing airflow elements such as doors, cracks, and ducts. Two such models are CONTAM and the EnergyPlus Airflow Network, both of which now have the capability of modelling contaminant transport indoors.

CONTAM (1) is an air quality and ventilation analysis tool developed by the National Institute of Standards and Technology (NIST) that can be used to calculate airflow, contaminant transport through airflow, and building occupant exposure to contaminants. Airflow in CONTAM is, like the EnergyPlus Airflow Network, based on the AIRNET model (2), while CONTAM has the additional capabilities of modelling contaminant concentrations inside buildings due to airflow-driven dispersal, adsorption and desorption to building materials, filtration, and deposition to building surfaces. CONTAM has been extensively validated (3-5), and offers a userfriendly means of understanding building ventilation and contaminant transport. CONTAM is strictly for airflow and contaminant analysis, and lacks the ability to simulate energy and thermal behaviour of buildings. 
Under typical operating conditions, the thermal performance of buildings causes dynamic zonal air temperatures, which can, in some cases, have an important impact on the airflow through a building and therefore contaminant transport. Pressure losses across an airflow path can be described using an energy equation:

$$
\Delta P=\left(P_{1}-P_{2}\right)-\left(\frac{\rho_{1} v_{1}^{2}}{2}-\frac{\rho_{2} v_{2}^{2}}{2}\right)+g\left(\rho_{1} z_{1}-\rho_{2} z_{2}\right)
$$

In Equation 1, the first term represents static pressure differences, the second dynamic pressure differences due to wind, and the third differences due to buoyancy. The second term shows that at high wind speeds, the total pressure difference is dominated by the differences in static pressures and the wind speed. The last term shows that at low wind speeds the dominant effect is the density of the air on each side of the flow path. The density of air is typically calculated using dry air and water vapour components of the air, meaning that the air density depends on the temperature and the amount of moisture in the air, given by:

$$
\rho=\frac{P_{d}}{R_{d} T}+\frac{P_{v}}{R_{v} T}
$$


Therefore, a change in the air temperature or the moisture content of air at low wind speeds can lead to a change in the pressure difference across a flow path, which in turn leads to a change in the movement of contaminants and water vapour.

While CONTAM is a very capable tool for calculating airflow rates and contaminant concentrations, a major limitation is that it is not a thermal modelling tool and so does not amend zonal air density in response to temperature changes due to building performance and occupant behaviour. There are a number of options available to CONTAM users who wish to account for the relationship between zonal air temperature and thermal performance of the building. The licensed dynamic thermal package TRNSYS has been coupled with CONTAM to enable combined airflow and heat transfer simulations for buildings, with bridging between the two tools allowing them to share simulations inputs and outputs (6). Alternatively, CONTAM users can either define a time-variable internal air temperature estimated for the zone, import internal air temperatures from physically measured sources, or import temperatures from the outputs of a different dynamic thermal model, such as EnergyPlus (7). Only the thermal modelling approaches can account for the complex interactions between the internal air temperature and building heat transfer mechanisms, such as ventilation convection, solar radiation, and fabric conduction. However, in 
un-coupled models this approach requires additional work to ensure that both models are identical, and adds significant time to the model development. In addition, the lack of feedback between two uncoupled models means that any changes to the CONTAM model that may impact internal temperatures (for example ventilation behaviour) require re-running thermal models and importing the new temperature schedules into CONTAM.

EnergyPlus (8) is an open-source whole building simulation program used for energy analysis and thermal load simulation. Airflow in EnergyPlus can be simulated using the multizone Airflow Network tool, an airflow model based on an early version of AIRNET and COMIS (9). The model is capable of simulating infiltration and exfiltration into a building due to indoor/outdoor pressure differences, building envelope permeability, natural and mechanical ventilation, as well as zone-to-zone airflows. The Airflow Network capabilities of EnergyPlus have been validated by comparison with measured data (10), and through an inter-model comparison with CONTAM (11). The ability to model pollutant transport in EnergyPlus has recently been introduced in the form of the Generic Contaminant Model (GCM), which allows users to model a single contaminant within a building. This enables the modelling of coupled thermal behaviour and contaminant transport within a single simulation package. In addition, UCL has 
developed an in-house model, Polluto, which allows for contaminant transport modelling in EnergyPlus 3.1. EnergyPlus GCM currently has an advantage over Polluto in being able to use indoor contaminant concentrations as flags to alter building operation, for example allowing ventilation systems to operate above a certain concentration threshold. Conversely, Polluto is capable of modelling multiple pollutants, while the GCM is currently restricted to a single contaminant.

This article describes the simulation of a simple single-zoned building in CONTAM, the EnergyPlus 8.0 GCM, and EnergyPlus-Polluto. An intermodel comparison is made between the models for $\mathrm{PM}_{2.5}$ infiltration into the building with dynamic internal temperatures derived from EnergyPlus. In addition, the results of simulations using dynamic internal temperatures are compared to simulations performed in CONTAM with constant internal temperatures, demonstrating scenarios where indoor air quality models decoupled to whole building energy models can perform unsatisfactorily.

\section{Methodology}

\subsection{Model Comparison}


There are inherent differences between the calculation methods employed by CONTAM and EnergyPlus that need to be considered in comparing the model performances. The assumptions used by EnergyPlus and CONTAM to calculate local wind speed and therefore air pressures at the external entrances to airflow paths are different, although result, as one would expect, in similar values. Wind pressures provided in weather files are modified in both tools to account for the differences between the wind speeds at the weather station, and the expected wind speeds at the height and location of the building. Variables in both tools can be adjusted in order to give similar results.

In addition, EnergyPlus and CONTAM also both report their predictions differently: CONTAM gives instantaneous values for contaminant concentrations over the simulation period, while EnergyPlus gives integrated values. As a result, either smaller time steps need to be used with CONTAM or trapezoidal interpretation used on the results, particularly where there are rapid changes in contaminant concentration. In addition, EnergyPlus employs so-called "WarmUp Days" which are run at the start of the EnergyPlus simulation to ensure that any thermal capacitance values are representative of the dwelling in the environment described by the weather file. Conversely, outputs from CONTAM are reported without an initial warm-up period, and so the concentrations of the two tools may not match 
over the initial period. For further information on the algorithms used by each program, see the CONTAM User Guide (1) and the EnergyPlus Engineering Reference (12).

Contaminant transport models are typically capable of modelling lowconcentration trace contaminants (for example $\mathrm{PM}_{2.5}$ ) and highconcentration non-trace contaminants (for example water vapour). $\mathrm{PM}_{2.5}$ was chosen to be the contaminant of interest for this study. As it can be produced by occupant activities within a building as well as infiltrating into a building through controlled or uncontrolled ventilation, $\mathrm{PM}_{2.5}$ has a strong airflow component when assessing occupant exposure (13). Water vapour was also considered as a non-trace contaminant in order to include it in CONTAM air density calculations.

To compare the performance of CONTAM with the EnergyPlus 8.0 GCM and EnergyPlus-Polluto, a single-zoned building $(4 \mathrm{~m} \times 5 \mathrm{~m} \times 2.8 \mathrm{~m})$ with no windows, doors, heating or pollution sources was created in the simulation tools. Airflow into the building was from infiltration through permeable walls $\left(3 \mathrm{~m}^{3} \mathrm{~h}^{-1} \mathrm{~m}^{-2} @ 50 \mathrm{~Pa}\right)$, with the roof and floor considered impermeable. Building envelope materials were modelled to provide a U-value of approximately $0.5 \mathrm{Wm}^{-2} \mathrm{~K}$ by selecting appropriate materials. The wall permeability was simulated by installing crack type flow paths near the 
bottom $(0.05 \mathrm{~m})$ and top $(2.75 \mathrm{~m})$ of each façade; the single-zoned building therefore has 8 airflow paths. The cracks were modelled with a power law equation assuming one-way airflow.

For the chosen permeability of $3 \mathrm{~m}^{3} \mathrm{~h}^{-1} \mathrm{~m}^{-2} @ 50 \mathrm{~Pa}$, a flow coefficient (C) of $0.0004411 \mathrm{~m}^{3} \mathrm{~s}^{-1} \mathrm{~Pa}^{-\mathrm{n}}$ was used for the $5 \mathrm{~m}$ wall, and $0.0003529 \mathrm{~m}^{3} \mathrm{~s}^{-1} \mathrm{~Pa}^{-\mathrm{n}}$ for the $4 \mathrm{~m}$ wall. The flow exponent (n) for both walls was set to 0.66 , as per Jones et al (14). A Chartered Institution of Building Services (CIBSE) weather file for London Heathrow (15) was used for both simulation packages; simulations were run for winter (January $1^{\text {st }}$ to January $21^{\text {st }}$ ) and summer (July $1^{\text {st }}$ to July $21^{\text {st }}$ ) conditions. As CONTAM is unable to independently calculate dynamic internal temperatures of the building, a preliminary run was performed in EnergyPlus 8.0, and the predicted internal temperatures converted into a continuous value file (.cvf) to define the internal temperatures in CONTAM. Any moisture-buffering effects of the building envelope were ignored.

$\mathrm{PM}_{2.5}$ was modelled with a molecular weight of $8 \mathrm{kgkmol}^{-1}$, with an initial internal concentration and constant external concentration set at $13 \mu \mathrm{gm}^{-3}$, a value approximately equal to the current mean outdoor $\mathrm{PM}_{2.5}$ concentration in London (16). $\mathrm{PM}_{2.5}$ was removed from the internal air with a deposition rate of $0.39[1 / \mathrm{h}]$ as per Ozkaynak et al. (17). Moisture was treated as a non- 
trace contaminant in CONTAM, and was therefore included in air density calculations. CONTAM airflow numerics were adjusted to account for the effect of flow element temperature on air density. The files were synchronised to ensure that they had exactly the same start times and time steps. Simulations were run with a reporting time step of 1 minute to minimise the discrepancy between the instantaneous output values of CONTAM and the integrated outputs of EnergyPlus. Zone air water content ratio $(\mathrm{g} / \mathrm{kg})$, and zone $\mathrm{PM}_{2.5}$ concentration were output on a minute by minute basis over a 3 week period for the software tools, and the differences between them compared.

\subsection{Limitations of Uncoupled Models}

In order to accurately simulate contaminant transport in a building, room temperatures should be appropriate for the modelled building. To demonstrate the impact of using an inappropriate air temperature on the internal concentration of $\mathrm{PM}_{2.5}$, the simulations were repeated in CONTAM with the internal temperature fixed. Internal temperatures were set to the average external temperature for the weather file during the three week simulation period $\left(2.7^{\circ} \mathrm{C}\right.$ for the winter period, $18.7^{\circ} \mathrm{C}$ for the summer period). In addition, the simulations were run with the internal CONTAM temperature set to the average internal temperatures as predicted by EnergyPlus $\left(4.3^{\circ} \mathrm{C}\right.$ for the winter period, $25.9^{\circ} \mathrm{C}$ for the summer period) in 
order to account for internal gains caused by the thermal performance of the building envelope.

$\mathrm{PM}_{2.5}$ and water content ratio were output on a minute-by-minute basis and the differences between the CONTAM model with static temperature and EnergyPlus GCM with a floating temperature analysed for the absolute differences. In addition, the relationship between external wind speed and internal $\mathrm{PM}_{2.5}$ and $\mathrm{RH}$ differences between the two models was examined.

\section{Results}

The results showed a strong agreement with the EnergyPlus 8.0 GCM and the in-house EnergyPlus Polluto model, with an absolute deviation between the models of $0.09 \%$ for the winter $(\sigma=0.09)$ and $0.09 \%(\sigma=0.07)$ for the summer simulation periods. Both the EnergyPlus GCM and Polluto model made $\mathrm{PM}_{2.5}$ predictions similar to those of the CONTAM model when CONTAM was provided with dynamic EnergyPlus-derived temperatures (Figure 1). Differences between EnergyPlus GCM and CONTAM when run during the winter period averaged 5.0\% $(\sigma=3.7)$; variations between the models may be attributable to different calculation methods and output reporting between the two tools. During the summer, differences between the model results for transient internal temperatures were found to decrease to $3.2 \%(\sigma=2.6)$. 
When internal temperatures were held constant in CONTAM, there were significantly larger differences between the predicted $\mathrm{PM}_{2.5}$ concentrations between the two models (Figure 1). For winter simulations, the difference between the transient EnergyPlus and static internal temperatures are 9.9\% $(\sigma=10.2)$ at $2.7^{\circ} \mathrm{C}$ and $7.1 \%(\sigma=8.4)$ at $4.3^{\circ} \mathrm{C}$ - approximately double the difference under transient conditions. Under summer conditions, differences between the transient model and the static model are $12.8 \%(\sigma=15.1)$ at $18.7^{\circ} \mathrm{C}$ and $7.0 \%(\sigma=7.0)$ at $25.9^{\circ} \mathrm{C}$. In both cases, the differences between the predictions are greater when the internal temperature was set at the average outdoor temperature rather than the average internal temperature as predicted by EnergyPlus; this emphasises the importance of accounting for the thermal performance of the building. When CONTAM simulations were run with the airflow numerics set to ignore the impact of temperature on air density, there were very large observed differences between transient and static CONTAM models and EnergyPlus at low wind speeds and summer high temperatures, indicating the importance of including air density numerics under such scenarios. 


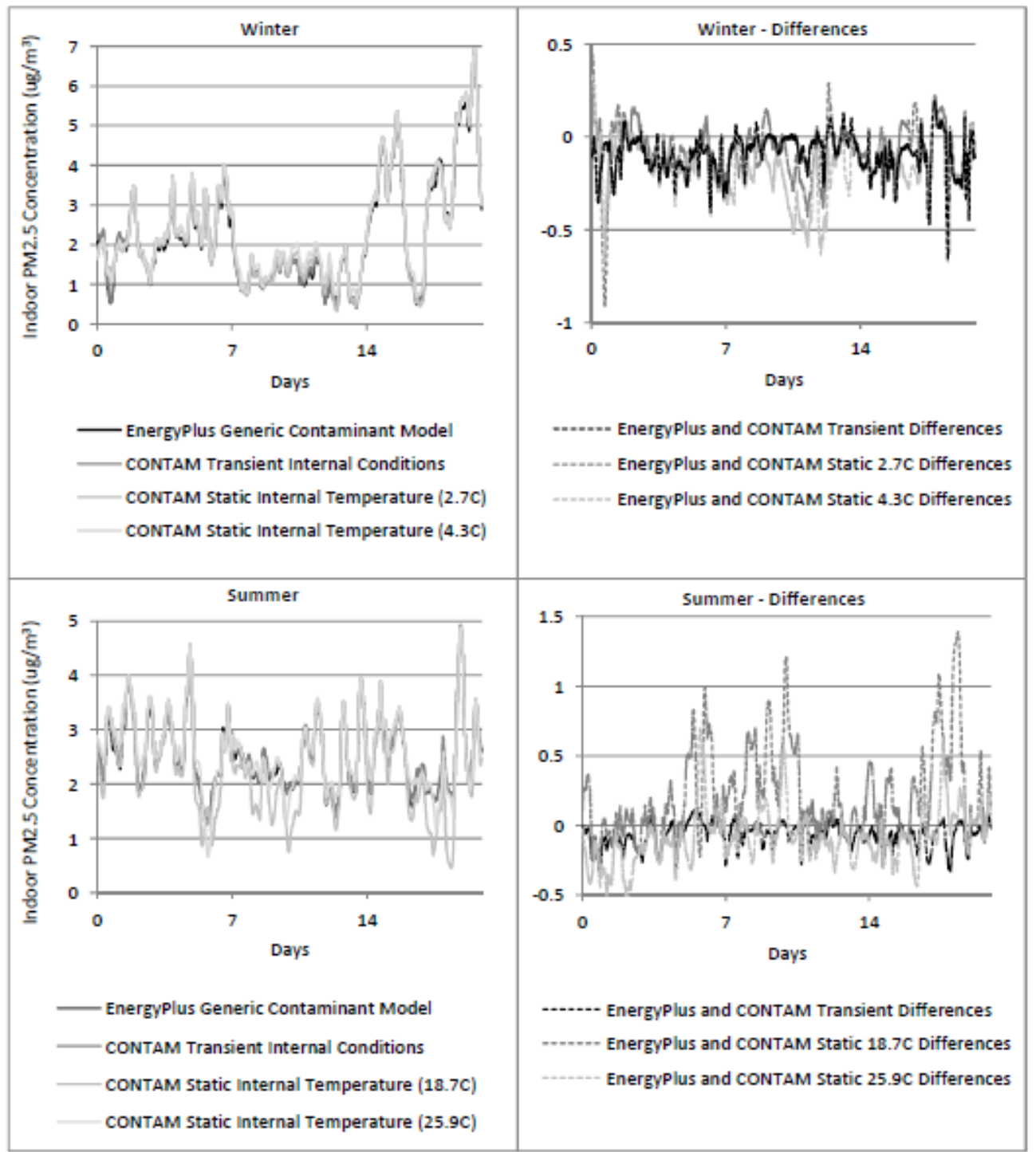

Figure 1. Indoor $\mathrm{PM}_{2.5}$ concentrations for winter (top) and summer (bottom)

simulations with transient and static internal temperatures. EnergyPlus-Polluto is not shown, as it overlaps entirely with the results from EnergyPlus-GCM.

Equation 1 describes how the influence of temperature may be most significant at low wind speeds and temperature-dependent buoyancy effects are dominant. The influence of wind speed on internal $\mathrm{PM}_{2.5}$ concentrations 
for winter and summer simulations can be seen in Figure 2. At low wind speeds and higher temperatures (e.g. summer), the differences in predicted $\mathrm{PM}_{2.5}$ levels between the models with static and transient internal temperature are highest.

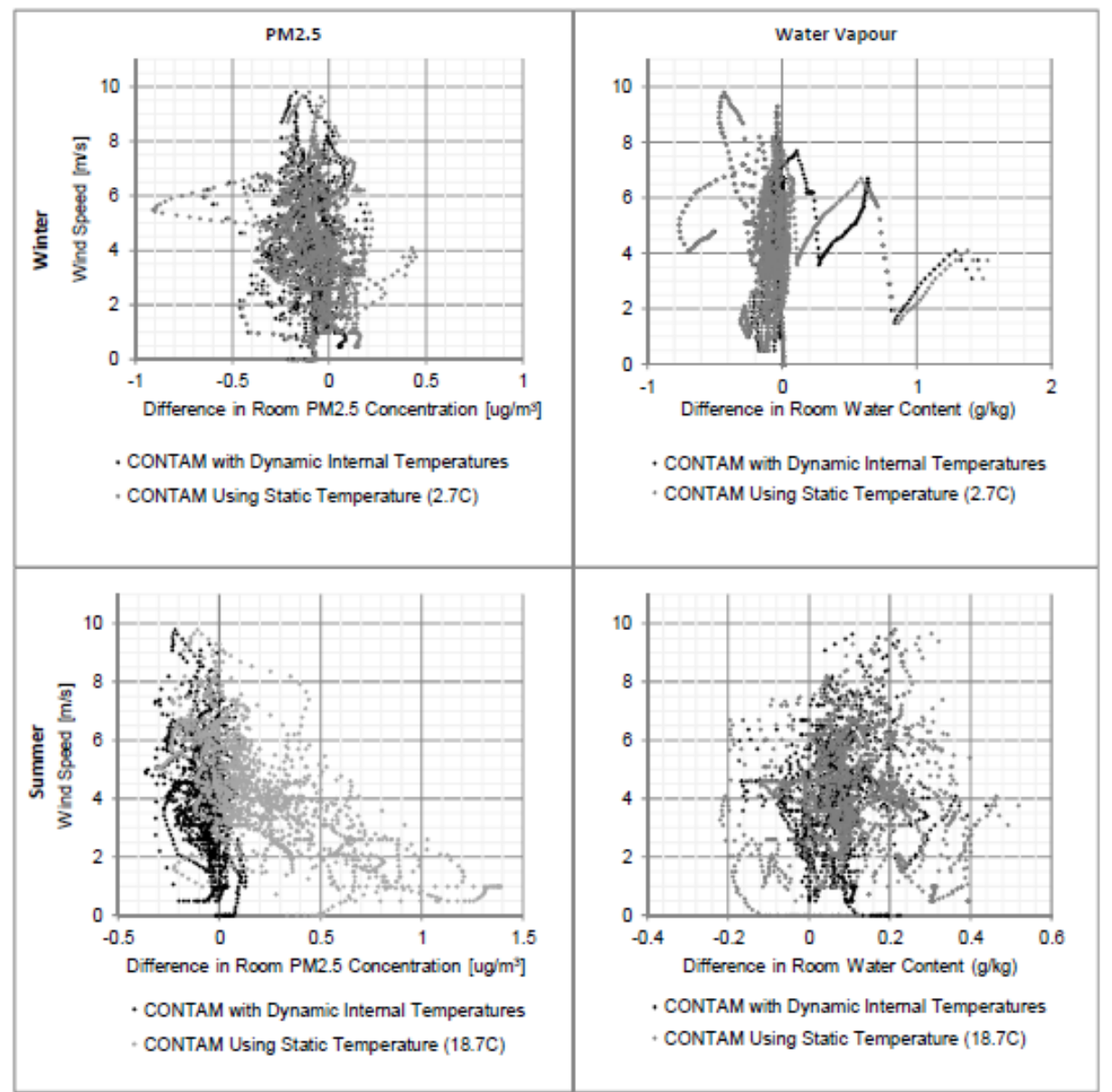

Figure 2. Differences in internal $\mathbf{P M}_{2.5}$ (left) and water vapour content (right) for winter (top) and summer (bottom) simulation periods according to outdoor wind speed for transient EnergyPlus and static CONTAM models. 


\section{Discussion}

The results demonstrate a good agreement between CONTAM, the EnergyPlus GCM, and the in-house Polluto model when the model parameters are set to be the same in the programs, thus providing confidence in the EnergyPlus tools. Simulation results from EnergyPlus GCM and the Polluto model are essentially identical, with very small differences attributable to rounding. Discrepancies between the two EnergyPlus models and CONTAM are small when the same temperatures are used, and may be attributable to three factors: (1) the differences in calculating the wind pressures on the external surfaces of the buildings between the EnergyPlus and CONTAM models; (2) the lasting effects of the EnergyPlus WarmUp days, and (3) the instantaneous CONTAM output reporting versus the integrated EnergyPlus reporting methods. In CONTAM, non-trace contaminants are included in air density calculations; by treating moisture as a non-trace contaminant, any differences in the calculated density of the air should be minimised.

Differences in the predicted $\mathrm{PM}_{2.5}$ concentration between the two models increase significantly when the internal temperatures are fixed in CONTAM rather than being derived from dynamic EnergyPlus calculations, demonstrating the importance of thermal performance of contaminant transport calculations. The differences were most significant when the 
constant temperature was set to the average outdoor temperature, and all thermal behaviour of the building envelope was ignored. At low wind speeds, the predicted indoor pollutant concentrations deviated by as much as $75 \%$ between models with dynamic and static internal temperatures.

The integration of a contaminant transport model into EnergyPlus gives a free fully-coupled thermal performance and contaminant transport model for buildings, eliminating the separate step of gathering internal temperature data for a CONTAM model for cases where the internal temperature is likely to fluctuate due to external weather conditions and building performance. In addition, EnergyPlus has the advantage of being coupled with a number of other modules that may impact contaminant transport. For example, the Heat and Moisture Transport (HAMT) model (18) can account for the hygrothermal behaviour of the building envelope, which can affect the internal water vapour concentration (non-trace contaminant) and subsequently the density of the air. Furthermore, another advantage of EnergyPlus is its ability to output integrated values rather than instantaneous values of pollutant concentration over time. In scenarios where short bursts of a pollutant can be generated, such as in cooking, CONTAM may fail to report elevated concentrations of pollutant if the time-step is not suitably short. In such scenarios, integrated output reporting saves writing-out time and memory as it is not necessary to output results with a small time-step. 
EnergyPlus GCM has the advantage over the Polluto model, in that it has been implemented in a more recent version of the EnergyPlus model, and can couple indoor contaminant levels with building performance - this feature could be used to model, for example, the influence of temperaturedependent window opening behaviour and the impact on indoor air quality. However, the EnergyPlus GCM is currently limited by being restricted to a single contaminant, while Polluto is capable of modelling many simultaneously.

While EnergyPlus may be a powerful tool for simulating the coupled thermal performance and airflow of a building, the model has a number of limitations in comparison to CONTAM and CONTAM-TRNSYS. The complexity of the EnergyPlus building simulation tool, and particularly the creation of an Airflow Network, may make the model inaccessible to nonexpert users. In addition, CONTAM is able to model a number of mechanical ventilation systems, whereas the ability of EnergyPlus to model mechanical ventilation systems using the Airflow Network is limited. In reality, most buildings will have some degree of heating and cooling that will allow them to operate within a 'fixed' range of temperatures, thus limiting the impact of the thermal performance of the building on air and contaminant movement that may occur if the temperatures were floating. 


\section{Conclusions}

The EnergyPlus GCM and Polluto models predict indoor $\mathrm{PM}_{2.5}$ concentrations and water content ratios very similar to those of CONTAM when both tools are given exactly the same building description and external environment. The programs agree to better than $5.0 \%$ on a minute by minute comparison over a three week summer period for winter and summer scenarios. When internal temperatures are fixed in CONTAM and allowed to float in EnergyPlus, significantly larger differences between the results are observed, indicating the importance of internal temperatures on airflow and contaminant transport within buildings. The results indicate that EnergyPlus GCM and Polluto are useful tools for calculating internal contaminant transport coupled to the thermal performance of the whole building system.

\section{References}

1. Walton G.N., Dols WS. CONTAM 2.4c User Guide and Program Documentation. Gaithersburg, MD; 2008 Oct.

2. Walton G. AIRNET: A Computer Program for Building Airflow Network Modeling. 1989 [cited 2013 Jun 4]; Available from: http://www.inive.org/Ibase search/search-detail-airbase001.asp? ID $=3464$

3. Haghighat F, Megri A. A comprehensive validation of two airflow models - COMIS and CONTAM. Indoor Air [Internet]. 1996 [cited 2013 Jan 23]; Available from: 
http://onlinelibrary.wiley.com/doi/10.1111/j.1600-

0668.1996.00007.x/abstract

4. Emmerich S. Validation of multizone IAQ modeling of residentialscale buildings: A review. ... SOCIETY OF HEATING

REFRIGERATING AND AIR ... [Internet]. 2001 [cited 2013 Jan

23]; Available from:

http://www.bfrl.nist.gov/IAQanalysis/docs/valfinal.pdf

5. Emmerich SJ, Howard-Reed C, Nabinger SJ. Validation of multizone IAQ model predictions for tracer gas in a townhouse. Building Services Engineering Research and Technology [Internet]. 2004 Nov 1 [cited 2014 Feb 17];25(4):305-16. Available from:

http://bse.sagepub.com/content/25/4/305.short

6. McDowell T, Emmerich S. Integration of airflow and energy simulation using CONTAM and TRNSYS.... SOCIETY OF HEATING ... [Internet]. 2003 [cited 2014 Feb 17]; Available from: http://www.bfrl.nist.gov/IAQanalysis/docs/tess.pdf

7. Hensen J. Modelling Coupled Heat and Airflow: Ping Pong Vs. Onions. DOCUMENT-AIR INFILTRATION CENTRE AIC ... [Internet]. 1995 [cited 2013 Feb 13]; Available from: http://www.esru.strath.ac.uk/Documents/pp_vs_onions.pdf

8. US-DOE. EnergyPlus V8 [Internet]. Washington, D.C.; 2013. Available from: http://www.eere.energy.gov/buildings/energyplus

9. Feustel H. COMIS - an international multizone air-flow and contaminant transport model. Energy and Buildings [Internet]. 1999 [cited 2013 Jun 4]; Available from:

http://www.sciencedirect.com/science/article/pii/S037877889800043 7

10. Gu L. Airflow network modeling in EnergyPlus. BUILDING SIMULATION [Internet]. 2007 [cited 2013 Jan 23]; Available from: http://www.fsec.ucf.edu/en/publications/pdf/FSEC-PF-428-07.pdf

11. Dutton S, Shao L, Riffat S. Validation and parametric analysis of EnergyPlus: air flow network model using contam. Third National Conference of IBPSA-USA, ... [Internet]. 2008 [cited 2013 Jan 23]; Available from: http://www.ibpsa.us/pub/simbuild2008/papers/SB08DOC-TS07-1-Dutton.pdf 
12. EnergyPlus. EnergyPlus Engineering Documentation. Berkeley, CA; 2013 Apr.

13. Wallace L, Howard-Reed C. Continuous Monitoring of Ultrafine, Fine, and Coarse Particles in a Residence for 18 Months in 19992000. Journal of the Air \& Waste Management Association [Internet]. Taylor \& Francis; 2002 Jul [cited 2014 Feb 17];52(7):82844. Available from: http://dx.doi.org/10.1080/10473289.2002.10470823

14. Jones, B.M., Das, P., Chalabi, Z., Davies, M., Hamilton, I., Lowe, R.J., Milner, J., Ridley, I., Shrubsole, C. and Wilkinson P. The Effect of Party Wall Permeability on Estimations of Infiltration from Air Leakage. International Journal of Ventilation. 2013;

15. CIBSE. Current CIBSE TRY/DSY hourly weather data set - 14 sites [Internet]. 2013. Available from:

https://www.cibseknowledgeportal.co.uk/weather-data

16. Shrubsole C, Ridley I, Biddulph P, Milner J, Vardoulakis S, Ucci M, et al. Indoor PM2.5 exposure in London's domestic stock: Modelling current and future exposures following energy efficient refurbishment. Atmospheric Environment [Internet]. 2012 Dec [cited 2013 Feb 5];62(null):336-43. Available from: http://dx.doi.org/10.1016/j.atmosenv.2012.08.047

17. Ozkaynak H, Xue J, Spengler J. Personal exposure to airborne particles and metals: results from the Particle TEAM study in Riverside, California. Journal of Exposure ... [Internet]. 1996 [cited 2013 Feb 14]; Available from: http://ukpmc.ac.uk/abstract/MED/8777374

18. Ridley I, Freeman J, Biddulph P, Davies M. Testing and Validation of UCL-HAMT. 2008 Jun; 